\title{
The combined effect of the T2DM susceptibility genes is an important risk factor for T2DM in non-obese Japanese: a population based case- control study
}

\author{
Kimiko Yamakawa-Kobayashi ${ }^{1 *}$, Maki Natsume ${ }^{1}$, Shingo Aoki', Sachi Nakano ${ }^{1}$, Tomoko Inamori ${ }^{1}$, \\ Nobuhiko Kasezawa ${ }^{3}$ and Toshinao Goda ${ }^{2}$
}

\begin{abstract}
Background: Type 2 diabetes mellitus (T2DM) is a complex endocrine and metabolic disorder. Recently, several genome-wide association studies (GWAS) have identified many novel susceptibility loci for T2DM, and indicated that there are common genetic causes contributing to the susceptibility to T2DM in multiple populations worldwide. In addition, clinical and epidemiological studies have indicated that obesity is a major risk factor for T2DM. However, the prevalence of obesity varies among the various ethnic groups. We aimed to determine the combined effects of these susceptibility loci and obesity/overweight for development of T2DM in the Japanese.

Methods: Single nucleotide polymorphisms (SNPs) in or near 17 susceptibility loci for T2DM, identified through GWAS in Caucasian and Asian populations, were genotyped in 333 cases with T2DM and 417 control subjects.

Results: We confirmed that the cumulative number of risk alleles based on 17 susceptibility loci for T2DM was an important risk factor in the development of T2DM in Japanese population $(P<0.0001)$, although the effect of each risk allele was relatively small. In addition, the significant association between an increased number of risk alleles and an increased risk of T2DM was observed in the non-obese group $(P<0.0001$ for trend), but not in the obese/ overweight group ( $P=0.88$ for trend).
\end{abstract}

Conclusions: Our findings indicate that there is an etiological heterogeneity of T2DM between obese/overweight and non-obese subjects.

\section{Background}

Type 2 diabetes mellitus (T2DM) is a complex endocrine and metabolic disorder. The interaction between multiple genetic and environmental factors is considered to contribute to the pathogenesis of the disease [1-3]. Most patients with T2DM suffer serious complications due to chronic hyperglycemia, including nephropathy, neuropathy, retinopathy and accelerated development of cardiovascular disease.

The prevalence of type 2 diabetes is continuing to increase in many countries, including Japan $[4,5]$.

\footnotetext{
* Correspondence: kobayasi@u-shizuoka-ken.ac.jp

'Laboratory of Human Genetics, School of Food and Nutritional Sciences, Graduate School of Nutritional and Environmental Sciences, Global COE

Program, University of Shizuoka, Shizuoka 422-8526, Japan

Full list of author information is available at the end of the article
}

Clinical and epidemiological studies have indicated that obesity is a major risk factor for T2DM, because obesity is associated with an increased risk of developing insulin resistance and impaired glucose tolerance [6,7]. When $\beta$-cells are no longer able to secrete sufficient amounts of insulin to overcome insulin resistance, impaired glucose tolerance progresses to T2DM [7].

The prevalence of obesity is also increasing worldwide, although there are large ethnic differences in the degree of obesity reached. In Japan, the prevalence of severe obesity (BMI $\geq 30 \mathrm{~kg} / \mathrm{m}^{2}$ ) is lower than that in Western countries, where the prevalence of overweight $(25 \leq$ BMI < 30) adults has been steadily increasing $[5,8]$. It is thought that genetically, insulin secretion compensation for insulin resistance is weaker in the Japanese than in

\section{Biomed Central}


Caucasians, and thus, being mildly overweight also conveys a risk factor for diabetes in Japan [8]. In fact, the prevalence of T2DM in the Japanese population is as high as in Western countries, although the prevalence of obesity is much lower than that seen in Caucasians $[4,5,8,9]$.

Recently, several genome-wide association studies (GWAS) have identified many novel susceptibility genes for T2D. To date, approximately 40 susceptibility loci for type 2 diabetes have been identified [10-17]. Most of these susceptibility loci were detected in Caucasians, and they have been widely confirmed to be susceptible loci for T2DM in Asian populations [17-23]. Furthermore, additional GWAS for Japanese and Chinese populations were performed and new susceptibility loci were detected [24-28], some of which have also been confirmed in Caucasians as well as Asian populations $[24,25,29]$. Thus, GWAS indicate that there are common genetic causes contributing to the susceptibility to T2DM in multiple populations worldwide, although clinical risk factors, such as BMI and insulin secretion levels, vary among the various ethnic groups with different genetic backgrounds or life styles [5]. Furthermore, most of the susceptibility loci identified through GWAS to date are likely to affect insulin secretion and $\beta$-cell function, while a few are potentially involved in insulin action [30,31].

In the present study, we analyzed the relationships between the genotypes of 17 susceptibility loci identified by GWAS and T2DM in a Japanese population-based case-control study. We also examined the combined effect of the cumulative number of risk alleles of the T2DM and obesity/overweight for the development of T2DM.

\section{Methods}

\section{Subjects}

This is a population based case-control study. The participants for this study were recruited from Japanese who underwent a routine medical check-up at a medical center near the University of Shizuoka on 2005. We have selected men $(\mathrm{N}=6094)$ under 65 years of age as subjects in this study. Of these, 378 men (6.2\%) were diagnosed with T2DM by physicians according to the World Health Organization (WHO) diagnostic criteria for T2DM (http://www.who.int/diabetes/publications/diagnosis_diabetes2006/en/). Of them, 333 men were included as T2DM subjects in this study, as complete genotype information on all 17 SNPs analyzed in this study was obtained. For the control subjects, 417 men (aged 45 to 65 years) were randomly selected from all subjects according to the following criteria: (1) their fasting plasma glucose levels were under $100 \mathrm{mg} / \mathrm{dl}(5.6$ $\mathrm{mmol} / 1)$, (2) their HbA1c levels were under 5.8\%, and
(3) complete genotype information on all 17 SNPs was obtained. All subjects provided written informed consent to participate in this study, and the study was approved by the Ethics Committee of the University of Shizuoka.

After overnight fasting, blood was collected from each subject. The clinical characteristics of the subjects were determined according to the medical check-up protocol.

\section{DNA analysis}

Genomic DNA was isolated from peripheral leucocytes by the phenol extraction method. We analyzed the genotypes of 17 SNPs in or near 17 susceptibility loci for T2DM. At first, we selected 10 susceptibility loci (SLC30A8, CDKN2A/B, KCNJ11, IGF2BP2, CDKAL1, HNF1B, HHEX, FTO, TCF7L2, PPARG), which had been detected in the first stage of GWAS for Caucasian [14], and four loci (CDC123, ADAMTS9, TSPAN8, JAFZ), which had been detected in a meta-analysis of three large GWAS [15], because they had been confirmed in several replication studies [17-23]. In addition, three SNPs (KCNQ1, C2CD4A, UBE2E2), which were discovered in GWAS using Japanese people, were examined $[24,25,28]$. However, three loci (WFS1, NOTCH2, THADA) which were also ascertained to be associated with T2DM in the first stage GWAS or the meta-analysis of three large GWAS [14,15], were excluded from this analysis due to low minor allele frequencies in Japanese $(<0.03)[17,23]$. Although more and more susceptibility loci for T2DM are being identified, we have not yet examined such new susceptibility loci.

The genotypes of these 17 susceptibility loci were determined for each subject using the PCR-restriction fragment length polymorphism method. The genotype call rate for each SNP was > 95\%. The genotype distributions of these 17 SNPs were in Hardy-Weinberg equilibrium $(P>0.05)$.

\section{Statistical analyses}

Each risk allele was defined as the allele associated with increased risk of T2DM in previous studies [23,28]. The each allele-specific odds ratios (ORs) with 95\% confidence intervals (CIs) and P-values for T2DM were calculated under the assumption of an additive model using logistic regression analysis, adjusting for age and BMI. In addition, the cumulative number of risk alleles was counted, in which individuals homozygous for nonrisk alleles were coded as 0 , heterozygous individuals were coded as 1 and individuals homozygous for the risk alleles were coded as 2 , with the assumption that each risk allele acted independently and contributed equally to the risk of T2DM. The effects of the cumulative number of risk alleles, BMI or obesity/overweight, and the interaction between the cumulative number of 
risk alleles and BMI or obesity/overweight on the prevalence of T2DM were assessed using multivariate logistic regression analysis.

Statistical analyses were performed using the JMP software package (SAS Institute, Cary, NC). The power to detect an association between each SNP and T2DM was estimated under current sample size and minor allele frequency observed in this study using "Quanto" (http://hydra.usc.edu/gxe/), assuming OR $=1.2$ and $\alpha$ level $=0.05$ (one-sided). The Cochran-Armitage test was used to examine the trend of an increase in the OR by an increasing number of the risk alleles.

\section{Results}

The characteristics of our subjects are presented in Table 1. Of the total 6094 subjects, the prevalence of diabetes, obesity, and being overweight were $6.2 \%, 2.6 \%$, and $27.0 \%$, respectively. The BMI, blood pressure, serum triglyceride, glucose and $\mathrm{HbA1c}$ were higher, and HDLcholesterol was lower, in subjects with T2DM compared with control subjects.

We then analyzed the relationships between common genetic variants of $17 \mathrm{~T} 2 \mathrm{DM}$ susceptibility loci that have

Table 1 Characteristics of the study subjects

\begin{tabular}{|c|c|c|c|c|}
\hline & $\begin{array}{c}\text { All } \\
\text { subjects } \\
n=6094\end{array}$ & $n=333$ & $n=417$ & $P$-value \\
\hline Age (years) & $49.9 \pm 8.3$ & $54.4 \pm 6.4$ & $53.7 \pm 5.1$ & 0.19 \\
\hline $\mathrm{BMI}(\mathrm{kg} / \mathrm{m} 2)$ & $23.7 \pm 3.0$ & $25.0 \pm 3.6$ & $23.1 \pm 2.7$ & $\begin{array}{l}< \\
0.0001\end{array}$ \\
\hline $\mathrm{SBP}(\mathrm{mmHg})$ & $\begin{array}{c}119.9 \pm \\
15.1\end{array}$ & $\begin{array}{c}126.3 \pm \\
15.6\end{array}$ & $\begin{array}{c}120.2 \pm \\
16.2\end{array}$ & $\begin{array}{l}< \\
0.0001\end{array}$ \\
\hline $\mathrm{DBP}(\mathrm{mmHg})$ & $76.6 \pm 11.4$ & $79.7 \pm 11.0$ & $76.6 \pm 11.8$ & 0.0004 \\
\hline $\begin{array}{l}\text { Total-cholesterol } \\
(\mathrm{mg} / \mathrm{dl})\end{array}$ & $\begin{array}{c}211.9 \pm \\
33.9\end{array}$ & $\begin{array}{c}212.7 \pm \\
35.0\end{array}$ & $\begin{array}{c}211.1 \pm \\
31.9\end{array}$ & 0.77 \\
\hline $\begin{array}{l}\text { LDL-cholesterol } \\
(\mathrm{mg} / \mathrm{dl})\end{array}$ & $\begin{array}{c}130.0 \pm \\
30.2\end{array}$ & $\begin{array}{l}131.2 \pm \\
29.8\end{array}$ & $\begin{array}{c}130.3 \pm \\
29.9\end{array}$ & 0.65 \\
\hline $\begin{array}{l}\text { HDL-cholesterol } \\
(\mathrm{mg} / \mathrm{dl})\end{array}$ & $57.8 \pm 16.3$ & $54.0 \pm 16.1$ & $58.7 \pm 16.4$ & 0.0002 \\
\hline Triglyceride (mg/dl) & $\begin{array}{c}140.0 \pm \\
107.0\end{array}$ & $\begin{array}{c}160.5 \pm \\
146.7\end{array}$ & $\begin{array}{l}134.9 \pm \\
110.6\end{array}$ & $0.012^{*}$ \\
\hline Glucose (mg/dl) & $\begin{array}{c}100.5 \pm \\
19.8\end{array}$ & $\begin{array}{c}153.8 \pm \\
40.7\end{array}$ & $91.8 \pm 4.9$ & $\begin{array}{l}< \\
0.0001^{*}\end{array}$ \\
\hline $\mathrm{HbA1c}(\%)$ & $5.3 \pm 0.76$ & $7.3 \pm 1.5$ & $5.1 \pm 0.33$ & $\begin{array}{l}< \\
0.0001\end{array}$ \\
\hline T2DM (\%) & 6.2 & 100 & 0 & - \\
\hline Obesity (BMI $\geqq 30$ ) (\%) & 2.6 & 6.9 & 1.0 & $\begin{array}{l}< \\
0.0001\end{array}$ \\
\hline $\begin{array}{l}\text { Overweight (BMI } \geqq 25 \text { ) } \\
(\%)\end{array}$ & 27.0 & 37.8 & 21.6 & $\begin{array}{l}< \\
0.0001\end{array}$ \\
\hline Hypertension (\%) & 13.5 & 29.3 & 13.2 & 0.0004 \\
\hline Current smorker (\%) & 39.8 & 44.6 & 41.4 & 0.62 \\
\hline
\end{tabular}

*Statistical test for triglyceride and glucose levels were calculated on logtransformed values

$P$-values between T2DM and contol groups were calculated by $t$-test or $\chi^{2}$-test Data are expressed as mean \pm SD or percentage been previously detected by GWAS and T2DM in Japanese men. Table 2 shows the risk allele frequencies of each SNP, and risk allele-specific OR, $P$-value and estimated power to detect the association, assuming $\mathrm{OR}=$ 1.2. The ORs and P-values were adjusted for age and $\mathrm{BMI}$ in a logistic regression analysis. Four risk alleles for $S L C 30 A 8, C D K N 2 A / B, C D C 123$, and $K C N Q 1$ were significantly associated with T2DM $(P<0.05)$, although three of them were not significant when Bonferroni's correction for multiple testing applied (significance level, $0.05 / 17=0.0029)$. Of the remaining loci, except for PPARG, ADAMTS9, TSPAN8 and JAZF1, the risk allele frequencies of T2DM subjects were higher than that of control subjects, although not statistically significant.

Next, we calculated the cumulative number of these 17 risk alleles that each subject possessed. The distribution of the cumulative number of risk alleles in T2DM subjects shifted to the right compared with that of the control subjects. The mean risk allele number in T2DM subjects $(16.7 \pm 2.5)$ was significantly higher than that in control subjects $(15.6 \pm 2.4)(P<0.0001, t$-test) (Figure $1)$. Multivariable regression analyses indicated that both the cumulative number of risk alleles and BMI or obesity/overweight were important predictors of T2DM $(P$ $<0.0001)$. In addition, we found interactions between the cumulative number of risk alleles and BMI or obesity/overweight for developing T2DM $(P=0.0080$ or $P$ $=0.015$, respectively) (Table 3 ). And the cumulative number of risk alleles was not an independent predictor of T2DM when the interaction between the number of risk alleles and obesity/overweight was incorporated in the regression model as a covariate $(P=0.81)$ (Table 3 , Model 4).

To examine the relationships between an increased number of risk alleles and T2DM, we stratified the subjects into four groups by quartiles of the risk allele numbers $(\mathrm{Q} 1, \leq 14 ; \mathrm{Q} 2,15,16 ; \mathrm{Q} 3,17,18$; and Q4, $\geq 19$, respectively). The $\mathrm{OR}$ associated with each quartile group compared with the reference group (Q1) are shown in Table 4. An increased number of risk alleles was associated with an increased risk of T2DM $(P<$ 0.0001 for trend).

Furthermore, to test for an interaction between the number of risk alleles and obesity/overweight on T2DM risk, we divided the subjects into two groups; the obese/ overweight group (BMI $\geq 25 \mathrm{~kg} / \mathrm{m}^{2}$ ) and the non-obese group (BMI $<25 \mathrm{~kg} / \mathrm{m}^{2}$ ). Significant association between an increased number of risk alleles and an increased risk of T2DM was observed only in the non-obese group ( $P$ $<0.0001$ for trend), and not in the obese/overweight group $(P=0.88$ for trend) (Table 4$)$. In addition, we analyzed the association between obesity/overweight and T2DM according to quartiles of the risk allele numbers. Obesity/overweight was a strong predictor of T2DM in 
Table 2 Individual effects of 17 risk alleles of the susceptibility loci on T2DM

\begin{tabular}{|c|c|c|c|c|c|c|c|c|}
\hline \multirow[b]{2}{*}{ Locus } & \multirow[b]{2}{*}{$\mathrm{db}$ SNP } & \multirow[b]{2}{*}{ Risk allele } & \multicolumn{2}{|c|}{ Risk allele frequency } & \multirow[b]{2}{*}{ OR } & \multirow[b]{2}{*}{ (95\% Cl) } & \multirow[b]{2}{*}{$P$-value } & \multirow[b]{2}{*}{ Power } \\
\hline & & & T2DM & Control & & & & \\
\hline SLC30A8 & rs13266634 & C & 0.64 & 0.57 & 1.95 & $(1.26-3.04)$ & 0.0026 & 0.41 \\
\hline$C D K N 2 A / B$ & rs10811661 & A & 0.61 & 0.54 & 1.96 & $(1.26-3.08)$ & 0.0030 & 0.41 \\
\hline CDC123 & rs11257622 & C & 0.26 & 0.21 & 1.99 & $(1.21-3.29)$ & 0.0068 & 0.31 \\
\hline KCNQ1 & rs2237892 & C & 0.64 & 0.58 & 1.85 & $(1.18-2.93)$ & 0.0073 & 0.40 \\
\hline KCNJ11 & rs5219 & $\mathrm{T}$ & 0.41 & 0.37 & 1.48 & $(0.96-2.28)$ & 0.074 & 0.40 \\
\hline$C 2 C D 4 A$ & rs7172432 & A & 0.59 & 0.54 & 1.48 & $(0.95-2.31)$ & 0.081 & 0.41 \\
\hline IGF2BP2 & rs4402960 & $\mathrm{T}$ & 0.34 & 0.30 & 1.45 & $(0.91-2.31)$ & 0.12 & 0.37 \\
\hline CDKAL1 & rs10946403 & G & 0.50 & 0.46 & 1.35 & $(0.88-2.08)$ & 0.17 & 0.42 \\
\hline HNF1B & rs7501939 & $\mathrm{T}$ & 0.35 & 0.32 & 1.35 & $(0.85-2.14)$ & 0.20 & 0.38 \\
\hline HHEX & rs1111875 & G & 0.30 & 0.28 & 1.25 & $(0.78-1.98)$ & 0.35 & 0.36 \\
\hline UBE2E2 & rs7612463 & $C$ & 0.84 & 0.83 & 1.31 & $(0.73-2.36)$ & 0.37 & 0.25 \\
\hline FTO & rs8050136 & A & 0.22 & 0.20 & 1.26 & $(0.73-2.15)$ & 0.40 & 0.30 \\
\hline TCF7L2 & rs7903146 & $\mathrm{T}$ & 0.06 & 0.05 & 1.39 & $(0.56-3.42)$ & 0.48 & 0.12 \\
\hline PPARG & rs1801282 & C & 0.97 & 0.97 & 1.49 & $(0.44-5.34)$ & 0.53 & 0.09 \\
\hline ADAMTS9 & rs4607103 & C & 0.60 & 0.60 & 0.81 & $(0.52-1.25)$ & 0.35 & 0.40 \\
\hline TSPAN8 & rs7961581 & C & 0.19 & 0.19 & 0.95 & $(0.54-1.69)$ & 0.87 & 0.29 \\
\hline JAZF1 & rs864745 & $\mathrm{T}$ & 0.79 & 0.80 & 0.93 & $(0.55-1.57)$ & 0.78 & 0.28 \\
\hline
\end{tabular}

Odd ratios and $P$-values were adjusted for age and BMI under the additive model

Power to detect association was estimated under current sample size and minor allele frequency, assuming OR $=1.2$

our Japanese subjects $(P<0.0001)$, however, for the subjects in Q3 and Q4 ( $\geq 17$ risk allele), obesity/overweight was not a significant risk factor for T2DM $(P>0.05)$ (Table 5). These findings indicate that there is an etiological heterogeneity of T2DM between obese/overweight and non-obese subjects.

\section{Discussion}

In this population-based case-control study, we have shown that the cumulative number of risk alleles based on 17 susceptibility loci for T2DM, identified through GWAS in Caucasian and Asian populations, was a significant risk factor in a Japanese population, although

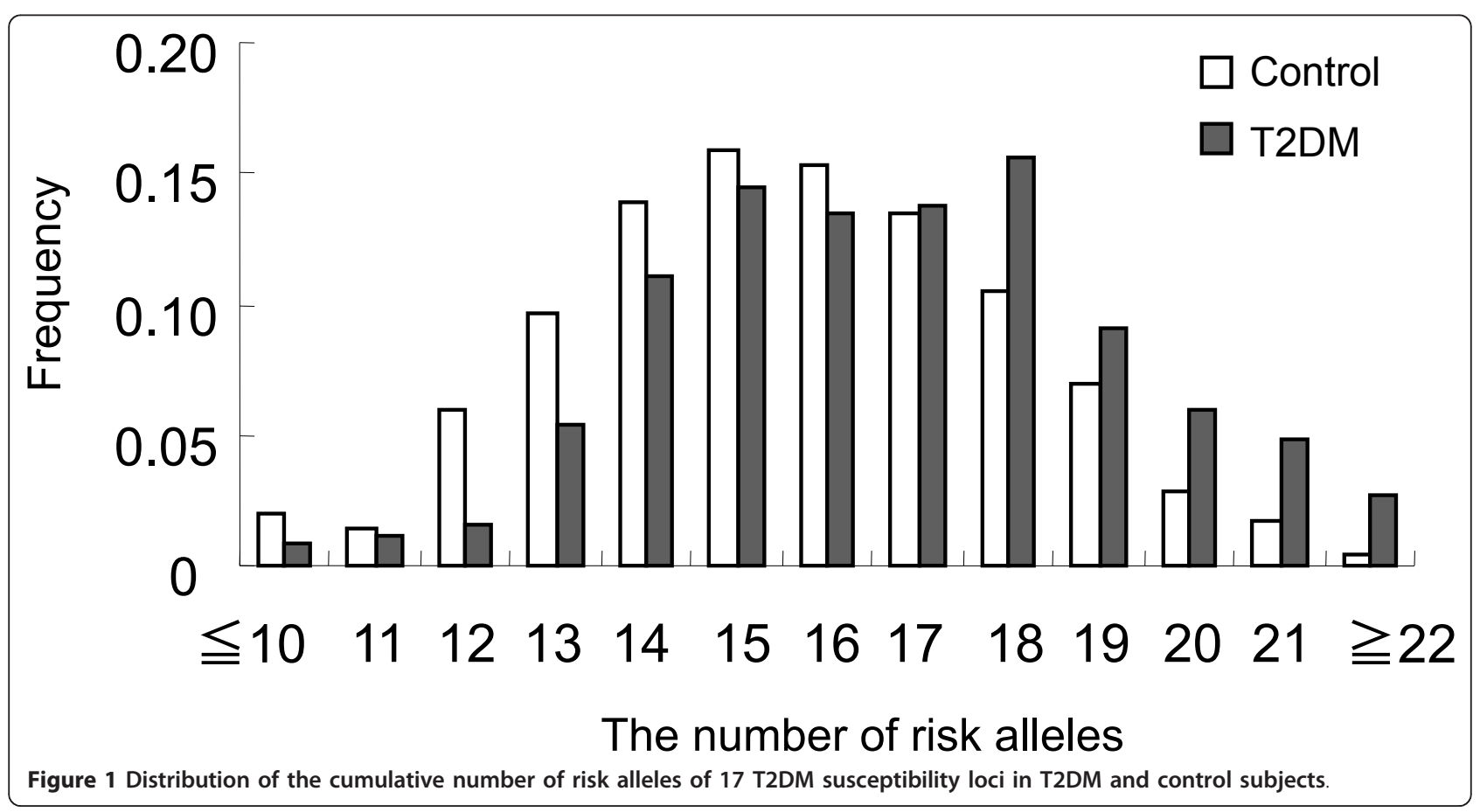


Table 3 Multivariable regression analyses for T2DM

\begin{tabular}{|c|c|c|c|c|c|c|}
\hline & Model 1 & & & Model 2 & & \\
\hline$\overline{R^{2}}$ & 0.10 & & & 0.11 & & \\
\hline intercept & -10.43 & & & -10.52 & & \\
\hline Determinant variables & $\beta$-coefficient & SE & $\mathrm{P}$ & $\beta$-coefficient & SE & $P$ \\
\hline No. of risk alleles & 0.18 & 0.033 & $<0.0001$ & 0.18 & 0.033 & $<0.0001$ \\
\hline $\mathrm{BMI}$ & 0.21 & 0.028 & $<0.0001$ & 0.22 & 0.029 & $<0.0001$ \\
\hline Age & 0.04 & 0.014 & 0.0038 & 0.04 & 0.014 & 0.0036 \\
\hline \multirow[t]{2}{*}{$\mathrm{BMI}+$ No. of risk allele } & & & & -0.029 & 0.011 & 0.0080 \\
\hline & Model 3 & & & Model 4 & & \\
\hline$\overline{R^{2}}$ & 0.089 & & & 0.097 & & \\
\hline intercept & -4.41 & & & -1.11 & & \\
\hline Determinant variables & $\beta$-coefficient & SE & $\mathrm{P}$ & $\beta$-coefficient & SE & $\mathrm{P}$ \\
\hline No. of risk alleles & 0.18 & 0.032 & $<0.0001$ & -0.026 & 0.11 & 0.81 \\
\hline Obesity/overweight & -1.22 & 0.20 & $<0.0001$ & -1.19 & 0.22 & $<0.0001$ \\
\hline Age & 0.04 & 0.014 & 0.0047 & 0.04 & 0.014 & 0.0047 \\
\hline Obesity/overweight + No. of risk allele & & & & 0.26 & 0.11 & 0.015 \\
\hline
\end{tabular}

Model 1 included the number of risk alleles, BMI and age as covariates

Model 2 included the number of risk alleles, BMI, age and the interaction between the number of risk alleles and BMI as covariates

Model 3 included the number of risk alleles, obesity/overweight and age as covariates

Model 4 included the number of risk alleles, obesity/overweight, age and the interaction between the number of risk alleles and obesity/overweight as covariates SE standard error

the effect of each risk allele was relatively small. Obesity is a very important risk factor for T2DM, however, many obese people do not develop T2DM, while many non-obese people do. In our population-based study, $9.5 \%$ of subjects in the obese/overweight group, and $4.7 \%$ of subjects in the non-obese group, had T2DM (data not shown). Impaired insulin resistance and insulin secretion are key determinants of T2DM development. It is well known that insulin resistance is associated with obesity, but insulin secretion is not affected by body constitution $[2,7]$.

The possibility of etiological heterogeneity of T2DM between obese/overweight and non-obese subjects cannot be overlooked. In fact, a significant association between an increased number of risk alleles and an increased risk of T2DM was observed only in nonobese group $(P<0.0001$ for trend), and an increased number of risk alleles was not a significant risk factor

Table 4 Relationships between increased number of risk alleles and T2DM

\begin{tabular}{|c|c|c|c|c|c|c|c|c|c|c|c|c|c|c|c|}
\hline \multirow{3}{*}{$\begin{array}{l}\text { Quartiles } \\
\text { of risk } \\
\text { alleles }\end{array}$} & \multicolumn{5}{|c|}{ All subjects $(n=750)^{*}$} & \multicolumn{5}{|c|}{ Obese/overweight $(n=243)^{* *}$} & \multicolumn{5}{|c|}{ Non-obese $(n=507)^{* *}$} \\
\hline & \multicolumn{2}{|r|}{$\mathbf{n}$} & \multirow[b]{2}{*}{ OR } & \multirow[b]{2}{*}{$(95 \% \mathrm{Cl})$} & \multirow[b]{2}{*}{$P$-value } & \multicolumn{2}{|r|}{$\mathrm{n}$} & \multirow[b]{2}{*}{ OR } & \multirow[b]{2}{*}{$(95 \% \mathrm{Cl})$} & \multirow[b]{2}{*}{$\begin{array}{l}P \text { - } \\
\text { value }\end{array}$} & \multicolumn{2}{|r|}{$\mathbf{n}$} & \multirow[b]{2}{*}{ OR } & \multirow[b]{2}{*}{$(95 \% \mathrm{Cl})$} & \multirow[b]{2}{*}{$P$-value } \\
\hline & T2DM & Control & & & & T2DM & Control & & & & T2DM & Control & & & \\
\hline \multicolumn{16}{|l|}{$(\leqq 14)$} \\
\hline $\begin{array}{l}\text { Q2 } \\
(15,16)\end{array}$ & 93 & 130 & 1.42 & $(0.93-2.19)$ & 0.11 & 43 & 26 & 1.15 & $(0.57-2.35)$ & 0.69 & 50 & 104 & 1.71 & $(1.01-2.91)$ & 0.045 \\
\hline Q3 & 98 & 100 & 1.95 & $(1.27-2.99)$ & 0.002 & 40 & 31 & 0.89 & $(0.44-1.79)$ & 0.75 & 58 & 69 & 3.13 & $(1.85-5.41)$ & $\begin{array}{l}< \\
0.0001\end{array}$ \\
\hline \multicolumn{16}{|l|}{$(17,18)$} \\
\hline Q4 & 75 & 50 & 3.14 & $(1.93-5.14)$ & $\begin{array}{l}< \\
0.0001\end{array}$ & 30 & 12 & 1.77 & $(0.77-4.23)$ & 0.18 & 45 & 38 & 4.20 & $(2.33-7.66)$ & $\begin{array}{l}< \\
0.0001\end{array}$ \\
\hline \multicolumn{16}{|l|}{$(\geqq 19)$} \\
\hline & & & & $\begin{array}{l}\mathrm{P} \text { for } \\
\text { trend }\end{array}$ & $\begin{array}{l}< \\
0.0001\end{array}$ & & & & $\begin{array}{l}P \text { for } \\
\text { trend }\end{array}$ & 0.88 & & & & $\begin{array}{l}\text { P for } \\
\text { trend }\end{array}$ & $\begin{array}{l}< \\
0.0001\end{array}$ \\
\hline
\end{tabular}

${ }^{*}$ ORs and $P$-values on T2DM for all subjects were adjusted with age and BMI

**ORs and $P$-values on T2DM for obese/overweight and non-obese subjects were adjusted with age 
Table 5 Effect of obesity/overweight on T2DM according to quartiles of risk allele numbers

\begin{tabular}{|c|c|c|c|c|c|c|}
\hline Quartiles & & T2DM & Contrrol & OR & $(95 \% \mathrm{Cl})$ & $P-$ \\
\hline $\begin{array}{l}\text { of risk } \\
\text { alleles }\end{array}$ & & $\begin{array}{l}(n= \\
333)\end{array}$ & $\begin{array}{l}(n= \\
417)\end{array}$ & & & \\
\hline All subjects & obese & 149 & 94 & 2.78 & $\begin{array}{c}(2.10- \\
3.72)\end{array}$ & $\begin{array}{c}<< \\
0.0001\end{array}$ \\
\hline & $\begin{array}{l}\text { non- } \\
\text { obese }\end{array}$ & 184 & 323 & & & \\
\hline Q1 & obese & 36 & 25 & 5.31 & $\begin{array}{l}(2.79- \\
10.33)\end{array}$ & $\begin{array}{c}< \\
0.0001\end{array}$ \\
\hline$(\leqq 14)$ & $\begin{array}{l}\text { non- } \\
\text { obese }\end{array}$ & 31 & 112 & & & \\
\hline Q2 & obese & 43 & 26 & 3.59 & $\begin{array}{l}(1.98- \\
6.61)\end{array}$ & $\begin{array}{c}< \\
0.0001\end{array}$ \\
\hline$(15,16)$ & $\begin{array}{l}\text { non- } \\
\text { obese }\end{array}$ & 50 & 104 & & & \\
\hline Q3 & obese & 40 & 31 & 1.61 & $\begin{array}{l}(0.89- \\
2.93)\end{array}$ & 0.11 \\
\hline$(17,18)$ & $\begin{array}{l}\text { non- } \\
\text { obese }\end{array}$ & 58 & 69 & & & \\
\hline Q4 & obese & 30 & 12 & 2.18 & $\begin{array}{c}(0.99- \\
5.02)\end{array}$ & 0.052 \\
\hline$(\geqq 19)$ & $\begin{array}{l}\text { non- } \\
\text { obese }\end{array}$ & 45 & 38 & & & \\
\hline
\end{tabular}

ORs and $P$-values were adjusted with age

for subjects in the obese/overweight group in this study ( $P=0.88$ for trend). However, the power of our study is insufficient to detect positive association in obese/overweight group due to the small sample size. It is necessary to confirm these finding in another large population.

It was reported previously that risk alleles affecting insulin action more significantly increase T2DM susceptibility in obese individuals, while risk alleles affecting insulin secretion confer a T2DM risk in non-obese individuals [32]. Most of the susceptibility loci analyzed in the present study appear to influence $\beta$-cell function, such as insulin secretion or $\beta$-cell proliferation, which reasonably explains why the association between an increased number of risk alleles and an increased risk of T2DM was observed only in our non-obese subjects. Furthermore, it is possible that the ability of insulin secretion is weak for subjects with an increased number of risk alleles. Unfortunately, we were unable to examine serum insulin levels of our subjects, and thus, the relationship between an increased number of risk alleles and insulin secretion in our subjects remains unclear. Further examination is required to determine $\beta$-cell function in our subjects.

Recently, several studies indicates the cumulative number of risk alleles is an important risk factor for T2DM in Asian population [20,22,33], moreover there is increasing interest that knowledge about genetic risk factors may be used to predict the risk of complex disorders such as T2DM [20,22,33-35]. Our data indicate that both the cumulative number of risk alleles and obesity/overweigh are important risk factors for T2DM, but that obesity/overweight is not a significant risk factor of T2DM in subjects with many risk alleles ( $\mathrm{Q} 3$ and $\mathrm{Q} 4$; risk allele number $\geq 17$ ). Most T2DM patients in Japan are characterized by a low BMI, it might be useful for Japanese population to count the number of risk alleles of susceptible loci to improve identification of high-risk subjects. However, our study is a population-based case-control study; therefore, we are unable to determine the predictive power of such susceptibility loci. Further prospective studies are required to translate such knowledge about genetic risk factors into clinical practice for prediction and prevention of T2DM in the general population.

\section{Conclusions}

We have shown that the cumulative number of risk alleles based on 17 susceptibility loci for T2DM, identified through GWAS in Caucasian and Asian populations, was a significant risk factor in a Japanese population, although the effect of each risk allele was relatively small. In addition, the association between an increased number of risk alleles and an increased risk of T2DM was observed only in non-obese group, and not in obese/overweight group. These data indicate that there is an etiological heterogeneity of T2DM between obese/overweight and non-obese subjects. In future, knowledge about genetic risk factors might be used in clinical practice for prediction and prevention of T2DM in the general population.

\section{Abbreviations}

SLC30A8: Solute carrier family 30 (zinc transporter) member 8; CDKN2A/B: Cyclin-dependent kinase inhibitor $2 \mathrm{~A}$ and $\mathrm{B}$ (melanoma p16, inhibits CDK4); CDC123: Cell division cycle 123 homolog (S. cerevisiae); KCNJ11: Potassium inwardly-rectifying channel subfamily J, member 11; IGF2BP2: Insulin-like growth factor 2 mRNA binding protein 2; CDKAL1: CDK5 regulatory subunit associated protein 1-like 1; HNF1B: HNF1 homeobox B; HHEX:

Hematopoietically expressed homeobox; FTO: Fat mass and obesity associated; TCF7L2: Transcription factor 7-like 2 (T-cell specific HMG-box); PPARG: Peroxisome proliferator-activated receptor $\gamma$; ADAMTS9: ADAM metallopeptidase with thrombospondin type 1 motif 9; TSPAN8: Tetraspanin8; JAFZ1: JAZF zinc finger 1; KCNQ1: Potassium voltage-gated channel KQTlike subfamily, member 1; UBE2E2: Ubiquitin-conjugating enzyme E2E 2; C2CD4A: C2 calcium-dependent domain containing 4A; PCR: Polymerase chain reaction; RFLP: Restriction fragment length polymorphism; SNP: Single nucleotide polymorphism; BMI: Body mass index; SBP: Systolic blood pressure; DBP: Diastolic blood pressure; LDL: Low-density lipoprotein; HDL: High-density lipoprotein; HbA1c: Hemoglobin A1c.

\section{Acknowledgements}

We are grateful to the subjects for their participation in this study. This study was supported by the Global COE program from the Ministry of Education, Culture, Sport, Science and Technology of Japan (MEXT). 


\section{Author details}

'Laboratory of Human Genetics, School of Food and Nutritional Sciences, Graduate School of Nutritional and Environmental Sciences, Global COE Program, University of Shizuoka, Shizuoka 422-8526, Japan. 'Laboratory of Nutritional Physiology, School of Food and Nutritional Sciences, Graduate School of Nutritional and Environmental Sciences, Global COE Program, University of Shizuoka, Shizuoka 422-8526, Japan. ${ }^{3}$ Department of Data Managements for Health Evaluation \& Promotion, Shizuoka Medical Center, Shizuoka 422-8033, Japan.

\section{Authors' contributions}

KYK managed the study, and carried out the genetic analyses, the genotyping experiments, drafting the manuscript. NM, SA, SN, TI carried out the genotyping experiments. NK and TG participated in the design of the study and recruitment of study subjects. All authors read and approved the final manuscript.

\section{Competing interests}

The authors declare that they have no competing interests.

Received: 2 September 2011 Accepted: 24 February 2012

Published: 24 February 2012

\section{References}

1. O'Rahilly S, Barroso I, Wareham NJ: Genetic factors in type 2 diabetes: the end of the beginning? Science 2005, 307:370-373.

2. Stumvoll M, Goldstein BJ, van Haeften TW: Type 2 diabetes: principles of pathogenesis and therapy. Lancet 2005, 365:1333-1346.

3. Dedoussis GV, Kaliora AC, Panagiotakos DB: Genes, diet and type 2 diabetes mellitus: a review. Rev Diabet Stud 2007, 4:13-24.

4. Wild S, Roglic G, Green A, Sicree R, King H: Global prevalence of diabetes: estimates for the year 2000 and projections for 2030. Diabetes Care 2004 27:1047-1053

5. Chan JC, Malik V, Jia W, Kadowaki T, Yajnik CS, Yoon KH, Hu FB: Diabetes in Asia: epidemiology, risk factors, and pathophysiology. JAMA 2009, 301:2129-2140.

6. Lazar MA: How obesity causes diabetes: not a tall tale. Science 2005, 307:373-375

7. Kahn SE, Hull RL, Utzschneider KM: Mechanisms linking obesity to insulin resistance and type 2 diabetes. Nature 2006, 444:840-846.

8. Yazaki Y, Kadowaki T: Combating diabetes and obesity in Japan. Nat Med 2006, 12:73-74.

9. Yach D, Stuckler D, Brownell KD: Epidemiologic and economic consequences of the global epidemics of obesity and diabetes. Nat Med 2006, 12:62-66.

10. Saxena R, Voight BF, Lyssenko V, Burtt NP, de Bakker PI, Chen H, Roix JJ, Kathiresan S, Hirschhorn JN, Daly MJ, et al: Genome-wide association analysis identifies loci for type 2 diabetes and triglyceride levels. Science 2007, 316:1331-1336

11. Scott $L$, Mohlke KL, Bonnycastle LL, Willer CJ, Li Y, Duren WL, Erdos MR, Stringham HM, Chines PS, Jackson AU, et al: A genome-wide association study of type 2 diabetes in Finns detects multiple susceptibility variants. Science 2007, 316:1341-1345.

12. Sladek R, Rocheleau G, Rung J, Dina C, Shen L, Serre D, Boutin P, Vincent D, Belisle A, Hadjadj $\mathrm{S}$, et al: A genome-wide association study identifies novel risk loci for type 2 diabetes. Nature 2007, 445:881-885.

13. Zeggini $E$, Weedon MN, Lindgren CM, Frayling TM, Elliott KS, Lango $H$, Timpson NJ, Perry JR, Rayner NW, Freathy RM, et al: Replication of genome-wide association signals in UK samples reveals risk loci for type 2 diabetes. Science 2007, 316:1336-1341.

14. Frayling TM: Genome-wide association studies provide new inghts into type 2 diabetes aetiology. Nat Rev Genet 2007, 8:657-662.

15. Zeggini E, Scott LJ, Saxena R, Voight BF, Marchini JL, Hu T, de Bakker PI, Abecasis GR, Almgren P, Andersen G, et al: Meta-analysis of genome-wide association data and large-scale replication identifies additional susceptibility loci for type 2 diabetes. Nat Genet 2008, 40:638-645.
16. Voight BF, Scott LJ, Steinthorsdottir V, Morris AP, Dina C, Welch RP, Zeggini E, Huth C, Aulchenko YS, Thorleifsson G, et al: Twelve type 2 diabetes susceptibility loci identified through large-scale association analysis. Nat Genet 2010, 42:579-589.

17. Imamura M, Maeda S: Genetics of type 2 diabetes: the GWAS era and future perspectives. Endocr J 2011, 58:723-739.

18. Omori S, Tanaka Y, Takahashi A, Hirose H, Kashiwagi A, Kaku K, Kawamori R, Nakamura Y, Maeda S: Association of CDKAL1, IGF2BP2, CDKN2A/B, HHEX, SLC30A8, and KCNJ11 with susceptibility to type 2 diabetes in a Japanese population. Diabetes 2008, 57:791-795.

19. Hu C, Zhang R, Wang C, Wang J, Ma X, Lu J, Qin W, Hou X, Bao Y, Xiang K, et al: PPARG, KCNJ11, CDKAL1, CDKN2A-CDKN2B, IDE-KIF11-HHEX, IGF2BP2 and SLC30A8 are associated with type 2 diabetes in a Chinese population. PLoS One 2009, 4:e7643.

20. Miyake K, Yang W, Hara K, Yasuda K, Horikawa Y, Osawa H, Furuta H, $\mathrm{Ng} \mathrm{MC}$, Hirota $Y$, Mori $\mathrm{H}$, et al: Construction of a prediction model for type 2 diabetes mellitus in the Japanese population based on 11 genes with strong evidence of the association. J Hum Genet 2009, 54:236-241

21. Tan JT, Ng DP, Nurbaya S, Ye S, Lim XL, Leong H, Seet LT, Siew WF, Kon W, Wong TY, et al: Polymorphisms identified through genome-wide association studies and their associations with type 2 diabetes in Chinese, Malays, and Asian-Indians in Singapore. J Clin Endocrinol Metab 2010, 95:390-397.

22. Xu M, Bi Y, Xu Y, Yu B, Huang Y, Gu L, Wu Y, Zhu X, Li M, Wang T, et al: Combined effects of 19 common variations on type 2 diabetes in Chinese: results from two community-based studies. PLoS One 2010, 5: e14022.

23. Waters KM, Stram DO, Hassanein MT, Le Marchand L, Wilkens LR, Maskarinec G, Monroe KR, Kolonel LN, Altshuler D, Henderson BE, Haiman CA: Consistent association of type 2 diabetes risk variants found in europeans in diverse racial and ethnic groups. PLoS Genet 2010, 6: e1001078.

24. Unoki H, Takahashi A, Kawaguchi T, Hara K, Horikoshi M, Andersen G, Ng DP, Holmkvist J, Borch-Johnsen K, Jorgensen T, et al: SNPs in KCNQ1 are associated with susceptibility to type 2 diabetes in East Asian and European populations. Nat Genet 2008, 40:1098-1102.

25. Yasuda K, Miyake K, Horikawa Y, Hara K, Osawa H, Furuta H, Hirota Y, Mori $H$, Jonsson A, Sato $Y$, et al: Variants in KCNQ1 are associated with susceptibility to type 2 diabetes mellitus. Nat Genet 2008, 40:1092-1097.

26. Shu XO, Long J, Cai Q, Qi L, Xiang YB, Cho YS, Tai ES, Li X, Lin X, Chow WH, et al: Identification of new genetic risk variants for type 2 diabetes. PLOS Genet 2010, 6:e1001127.

27. Tsai FJ, Yang CF, Chen CC, Chuang LM, Lu CH, Chang CT, Wang TY, Chen $\mathrm{RH}$, Shiu CF, Liu YM, et al: A genome-wide association study identifies susceptibility variants for type 2 diabetes in Han Chinese. PLOS Genet 2010, 6:e1000847.

28. Yamauchi T, Hara K, Maeda S, Yasuda K, Takahashi A, Horikoshi M, Nakamura M, Fujita H, Grarup N, Cauchi S, et al: A genome-wide association study in the Japanese population identifies susceptibility loci for type 2 diabetes at UBE2E2 and C2CD4A-C2CD4B. Nat Genet 2010, 42:864-868.

29. Sim X, Ong RT, Suo C, Tay WT, Liu J, Ng DP, Boehnke M, Chia KS, Wong TY, Seielstad M, et al: Transferability of type 2 diabetes implicated loci in multi-ethnic cohorts from Southeast Asia. PLoS Genet 2011, 7:e1001363.

30. Wolfs MG, Hofker MH, Wijmenga C, van Haeften TW: Type 2 diabetes mellitus: new genetic insights will lead to new therapeutics. Curr Genomics 2009, 10:110-118.

31. Billings LK, Florez JC: The genetics of type 2 diabetes: what have we learned from GWAS? Ann N Y Acad Sci 2010, 1212:59-77

32. Cauchi S, Nead KT, Choquet $H$, Horber F, Potoczna N, Balkau B, Marre M, Charpentier G, Froguel P, Meyre D: The genetic susceptibility to type 2 diabetes may be modulated by obesity status: implications for association studies. BMC Med Genet 2008, 9:45.

33. Qi Q, Li H, Wu Y, Liu C, Wu H, Yu Z, Qi L, Hu FB, Loos RJ, Lin X: Combined effects of 17 common genetic variants on type 2 diabetes risk in a Han Chinese population. Diabetologia 2010, 53:2163-2166. 
34. Janssens AC, loannidis JP, van Duijn CM, Little J, Khoury MJ, GRIPS Group: Strengthening the reporting of genetic risk prediction studies: the GRIPS statement. Eur J Epidemiol 2011, 26:255-259.

35. Willems SM, Mihaescu R, Sijbrands EJ, van Duijn CM, Janssens AC: A methodological perspective on genetic risk prediction studies in type 2 diabetes recommendations for future research. Curr Diab Rep 2011, 11:511-518.

Pre-publication history

The pre-publication history for this paper can be accessed here: http://www.biomedcentral.com/1471-2350/13/11/prepub

doi:10.1186/1471-2350-13-11

Cite this article as: Yamakawa-Kobayashi et al:: The combined effect of the T2DM susceptibility genes is an important risk factor for T2DM in non-obese Japanese: a population based case-control study. BMC Medical Genetics 2012 13:11.

\section{Submit your next manuscript to BioMed Central} and take full advantage of:

- Convenient online submission

- Thorough peer review

- No space constraints or color figure charges

- Immediate publication on acceptance

- Inclusion in PubMed, CAS, Scopus and Google Scholar

- Research which is freely available for redistribution

Submit your manuscript at www.biomedcentral.com/submit 